\title{
Cultural Intelligence as a Mediating Factor among International Students Adaptability in India
}

Khyati K*, Joel Johnson†and VanditaMohtał

\section{Abstract}

In this paper,the authors have analysed the problems faced by foreign students in India while adapting to the Indian academic and work environment. For conducting the research, numerous international students from Christ (Deemed to be University), Bangalore were interviewed, and the problems faced by them were documented. The Likert scale has been used to measure Cognitive, Emotional and Physical CQ of both Indian and international students. The paper has been curated ina case study approach through primary research which forms as a base for understanding the situation of foreign students in India and recommending suggestions for reducing cultural conflict.The paper identifies language, cuisine and limited social circle as the major challenges faced by foreign students. The paper also evaluates the role that cultural intelligence plays as an enabling factor for better cross-cultural adjustment. The researchers have also suggested techniques for inculcating cultural intelligence among students.

Keywords: Cultural Intelligence, Cultural Conflict, Cultural Quotient, International Students

*Graduate Trainee (BBA Hons Graduate, CHRIST), Godrej \& Boyce, India; anglekhyati05@gmail.com

†Analyst, (BBA Hons Graduate, CHRIST), KPMG Assurance and Consulting Services LLP, India; joel.johnson743@gmail.com

¥Account Manager, (BBA Hons Graduate, CHRIST), DeltaX, India vanditamohta2@gmail.com 


\section{Introduction}

With India becoming a major part of the world economy, an increasing number of good quality universities and increasing globalisation has led to a large number of foreign students to come to India. There have been a lot of cases of confrontation between Indian and foreign students. These cases constantly hit the headlines, and many of them turn violent too. In such scenarios, it is important to analyse the reasons for these clashes. The difference in culture seems to be the major cause of this friction between local and foreign student communities. Culture, according to (Serjanaj, 2016) "consists of the beliefs, behaviours, objects, and other characteristics common to the members of a particular group or society". The lack of knowledge and awareness about different cultures leads to a lack of understanding between local and international communities leading to friction between them. With increasing globalisation, cultural intelligence over the past decade has emerged as a very important concept in bridging the gap between different cultures. Cultural intelligence (Tay, 2007) is the ability of a person to understand and adapt freely and easily in a different culture and interact effectively with them, thus producing maximum positive results. Cultural intelligence has been a driving factor around the world in increasing productivity by reducing conflicts. The lack of adaptability of people from different cultures is a direct result of the lack of cultural intelligence and thus calls for the development of the same among people. Cultural intelligence, by reducing cross-cultural confrontation, can be a mediating factor in helping foreign students to adapt to Indian culture and also for Indian students to be more sensitive towards foreign students. Thus, inculcating CQ among students can be an effective strategy to reduce differences among Indian and foreign student communities and building a more vibrant academic environment.

\section{Review of Literature}

\subsection{International Students}

Akinkugbe (2013) studies how international undergraduate students comprehend the impact of education in a different crosscultural environment. He found out that international student face 
problems in coping up with the new cultural environment. Every year more than 700,000 students pursue higher studies in the United States or Canada, according to Lipson (2008). They need to adopt a new university's system of learning and new cultural environment.Manahil Wajid (2017)stated that foreign students mostly face problems related to academic change than related to social or peer status. According to him, various cultural and social factors affect the academic life of international students. According to Prashant (2018), the outflow of Indian students to other countries are more as compared to the inflow of foreign students in India for higher education.

\subsection{Issues related to Acculturation}

According toGazzoli (2013), all the international students who move to foreign countries for their higher studies, face problems related to the acculturation process, which impacts their social and educational well-being. He conducted interviews of the international students from Panama and later analysed that students bear psychological, social and physical problems. Nishii (2013) pointed out that people of different cultures tend to face a situation of tension in the same workplace. People working in the organisation are not integrated into the acculturation process and don't accept new things as they don't have an open mind. Guzel (2016) undertook a comparative analysis relating to acculturation and acculturative stress among domestic and international students. Acculturation refers to assimilation to a different dominant culture. The paper thus studies on how acculturation affects domestic and international students' acculturative stress. The outcome, as expected, was that international students face more acculturative stress than the domestic students of the USA.

\subsection{Cultural Differences}

According to Bradley (2002), there are several types of cultural differences which have been faced among international students in different countries. One of the cultural difference among foreigners is assertiveness. An empirical study has been done to find out the perceived assertiveness among foreign students. It has been considered as an important factor for personal mental health, selfesteem, and advanced feelings. Furthermore, collectivism is 
another cultural difference which is found among the international students. For example, various findings state that Asian international students are considered as less assertive and more passive as compared to other international students.

As stated by Arthur (2004), understanding these differences isvery challenging.It shows that it is very difficult to adjust to different norms and culture of different places which makethe whole process challenging, according to Sumer (2009). Coping witha new learning environment is difficult as each and every norm of different culture vary. Campbell (2011) talked about the solutions to the problem and made certain recommendations about how to reduce such differences. He thereby suggested the host country students give the international students social and personal support so that they don't feel alienated in the host country. Chase (2011) also suggested that an interpersonal programme can help the foreign students develop a sense of belongingness, reduction in anxiety and many more. This will also help in decreasing cross-cultural differences in the future.

\subsection{Psychological Changes}

Another major problem which is found among the international students isthe psychological problems, as stated byBoonchum (2009). According to the research, international students positively behave in the new cultural environment, but some of the individuals face more problems because of their own individual attitudes and behaviours. These foreign students try to adapt tothe new cultural environment, according to Walton (2012). He stated that going to college for higher education is an exciting experience, but most of the students suffer from homesickness which affects them psychologically. Students also go through loneliness and depressionbecause of homesickness. These factors also create a fear of failure in academics, which put a lot of pressure among the students to perform well. But sometimes, because of the mental problems caused by homesickness, they are not able to perform well, which in a way affects their academic life.

Finally, Qing Gu (2009) explored the experiences of the international students in terms of their development as well as their adaptation in new cultural environment. He suggested that 
personal factors of the individuals affect their competence in terms of adapting themselves in a new environment.

\subsection{Cultural Differences and International Students}

Hartini (2017) analysed how cultural intelligence has had an impact on international students' engagement. The education industry in Malaysia has seen an increased inflow of international students who face cultural shock and adaption difficulties in a new environment. Cultural intelligence refers to an individual's ability to adapt to cultural changes and act accordingly among various other cultural differences. Students' engagement refers to the involvement in activities of the educational institution. According to the research paper, international students opt to study in a foreign university so as to acquire experiences that result in personal growth. The paper concludes, stating that cultural intelligence is an essential element that accelerates international students' engagement.

Wang (2015) stated that a major challenge in the organisational world today is the management of cross-cultural diversity. The objective of this paper was to understand the contribution of cultural intelligence in the adjustment of international students in the United States. The research found that cultural intelligence trajectories are, in fact, linked with positive psychological indicators than with negative indicators. Future orientations of students are also discussed in the paper. Thomson (2006) focused on a particular university in Australia and how international students have faced cultural shock on shifting into a new environment. It discusses the social connectedness, lifestyle balance, mental health and cultural stress among the international students in the university. The findings revealed that cultural stress largely depends on an individual's background, their evaluation of academic progress perceived, and communication skills within a new culture. All of these elements account up for cultural intelligence. Jian Wang (2002) discusses cultural differences with the view of effective communication styles and processes in the field of information services. The research was undertaken on the basis of results drawn from samples selected from various universities. 


\subsection{Cultural Intelligence and Impact on Organisations}

Peterson (2017) stated the importance of intercultural understanding and education, i.e. the concept of Cultural Intelligence. It states how cultural intelligence affects the working environment in multinational corporations and questions the relationship between Intelligence Quotient (IQ) and its effect on adaption to new cultural changes. It proposes to include motivational, meta-cognitive, and behavioural components for training that is required by a global manager. Higgins (2005) emphasises on the fact that Intelligence Quotient, Emotional Quotient and leadership behaviours are influenced by Cultural Intelligence in global leadership success as it helps in better understanding of different cultural leadership programs of multinational firms.

Ang (2003) emphasises the importance of cultural intelligence in the present era of increased multinational corporations and working in international teams. The inability of cooperation due to cultural differences results in conflicts and adversely affects organisations. The book also states how a person with high Cultural Intelligence is better with adapting to a new cultural environment than one with low Cultural Intelligence. The paper helps an individual to realise its natural ability to interpret its environment and construct its CQ. It addresses issues like global management, meta-cognition, cultural adjustment and intercultural communication. It combines motivation with cognitive ideas of intelligence and thus provides a new pathway for researchers.

Inkpen (2008) discusses in detail the importance of organisation level cultural intelligence with offshoring (Form of International Business Venture) as its basis of discussion. A three-dimensional framework comprising of intercultural capabilities was created to discuss managerial and theoretical implications. Livermore (2008) emphasises on how cultural intelligence is constantly helping organisations and individuals achieve their objectives by creating a cooperative work environment. It also discusses how cultural intelligence helps to gather creative ideas, experiences and learning from the various cultural sources available. Glazer (2017) discusses expatriate failures and how that affects organisations. There is an increasing urge for the incorporation of cultural intelligence and 
cross-cultural competence among individuals in organisations and institutions with the introduction of globalisation in the world. For organisations to succeed, effective management along with improvement in cultural intelligence is a must.

\subsection{Cultural Intelligence and its Evaluation}

Deardoff (2006) wanted to formulate a proper evaluation method of cross-cultural competence. The data was collected by a set of samples of higher education management teams. The conclusion accounted up for formulation of effective evaluation methods using qualitative and quantitative methods which were agreed upon by both the scholars and the administrators. Mendenhall (1990) found out that there has been an increase in internationalisation in the various sectors of society, which has increased inter-cultural contact with people across the world. However, since most of this contact has not been very successful, inter-cultural training must be focused on. On research, it was found that cross-cultural training is effective in general. The paper provides a framework on the basis of social learning theory to fill in gaps for research undertaken in the past and to provide a basis for research in the future.

\subsection{Development of Cultural Intelligence}

Miriam (2013),in his study, says that online experiential programmes can be conducted for students in a multicultural group over the internet.Thishas been proven to be a good source of inculcating practical cultural intelligence characteristics into students and helps put theoretical knowledge gained in college into a practical context. The learnings from the project havebeen seen to remain in students for a longer period of time. Jacob (2013), in his study, specifies that cross-cultural management courses taught in an academic setting havebeen seen to increase the overall cultural intelligence of students. Students with the only experience in multicultural work environments who haven't taken any crosscultural management courses have been seen to have lower cultural intelligence. According to Fischer (2011), lecture series and simulation games have been proved to improve cultural competence among students, especially the ones with a more open mind. These programmes help in improving their knowledge about different cultures and help in improving overall cultural 
competence. Melody Chao (2016) figured out that exchange programmes for students which acts as a strong method to increase cross-cultural interaction act as a strong way for students to increase their cultural competence and helps in overall cultural intelligence development of students. Evan Wooda (2015) found out that short term study tour acts as an experiential learning method and helps in converting the experience into knowledge which further enhances overall cultural intelligence. Study tours have been seen to positively improve metacognitive $C Q$, cognitive CQ and motivational CQ. Rebecca (2015) specifies that events like classroom training, the training group work, role-play helped in increasing overall CQ. These structured activities help in improving the cultural intelligence of students.

\section{Research Gap}

Many studies have been previously conducted for understanding the problems faced by students who go to Malaysia, United States, United Kingdom, and Canada for their higher education. No study has been conducted so far, which talks about the difficulties faced by international students who come to India even though the country is famous for its diverse culture. There was no research done for finding out the problems with the solutions in India, which is known for its diversity.

Due to the globalisation and increased inclusion of international students in India, it is very important to conduct research about the main problems which international students face in India. It is very important to conduct the study to help reduce friction among local and foreign students.

Not even a single research has been done, which is applicable to the Indian scenario, which is the main reason for conducting the research on this topic. We will be bridging the gap by conducting this study in India. 


\section{Research Methodology}

\subsection{Objectives of the study}

There are various objectives of conducting this study which isas follows-

- To study the experiences of foreign students in India

- To study the challenges faced by foreign students in adapting to a new cultural learning environment

- To examine the techniques used by international students to adapt to their new cultural learning environment

- To measure and study the cultural intelligence quotient of foreign students studying in India

- To analyse the current level of cultural intelligence among students and its impact on their cross-cultural relationships and experiences

- To study the impact of the level of cultural intelligence among domestic students on international students

\subsection{Scope of the study}

This study mainly attempts to analyse the difficulties faced by foreign students in adapting themselves in a new cultural environment. There was no research conducted regarding the foreign students' adaptability in India even though it is known for its diversity. This study will help us to make people of the host country understand the importance of accepting international students. The study also measures the cultural intelligence of the interviewees and compares those results with their individual experiences.

\subsection{Data Collection/Sources of the study}

The different sources of data collection sources includeopen-ended interviews, observation during interviews and the survey, which is in line with the qualitative research method of phenomenology.Data have been collected through primary research wherein foreign students of Christ (Deemed to be University) were interviewed to collect relevant information and go 
forward with the research. The main purpose of using the primary source was to avoid discrepancies.

\subsection{Tools and Techniques used}

- Descriptive phenomenological analysis(Akinkugbe, 2013)has been used to study the difficulties of international students in adapting themselves in the new environment and understand their individual experiences by asking them interview questions(see appendix) in a face to face format.

- Likert scale questionnaire from (Ang, 2003) was used to diagnose the cultural intelligence of both the local students and the international students in India to analyse the cognitive, physical and emotional CQ of the students.

\subsection{Conceptual framework}

Face to face interviews with five international studentsfrom Congo, Germany, Thailand, Saudi, and Nepal were conducted who gave us first-hand information about the problems they faced when they came to India for their higher studies. It also helped us to understand the experiences of each individual. Cultural intelligence of all the participants have been measured using the framework given by (Ang, 2003) in their acclaimed HBR publication wherein Scaling Method is used to measure the cultural intelligence of all the participants. It constitutes of three sources, i.e. cognitive CQ, which is related to mind, physical CQ, which is related to the body, and emotional CQ, which is related to the heart. Socultural intelligence of all the participants hasbeen measured with the help of the Likert Scale, which is shown in the Appendix-1.Then descriptive phenomenological analysis was used to analysethe relationship between the cultural intelligence of the individual and their own unique experiences.A case study approach has been used to articulate the results of the interview and structured cultural intelligence test.

\section{Analysis and interpretation}

For our research, we conducted a face to face interview with some of the international students who gave us information about the problems which they faced when they came down to India for their 
higher studies. We talked to students from Congo, Germany, Thailand, Saudi, and Nepal. Conducting a personal interview gave us more insight intothe problems they faced in the country and how did they overcome those problems, etc. Each individual came up with a different problem which they faced related to their social, academic life. We have made case studies for each student where they will be stating the difference in the culture which they came across in India. Cultural intelligence of all the participants hasbeen measured with the help of the Likert Scale, which is shown in the Appendix-1. Generally, an average of less than 3 reflects calling for an improvement, while an average of more than 4.5 reflects a great CQ strength.

\section{Case Study-1 (Student Name- AyonjanSaha, Place of Origin- Saudi)}

AyonjanSaha is born and brought up in Saudi. He came to India before his class 12 . He saw various differences in the learning environment between the two countries. The concept of co-ed schooling was new to him; however, it did not create a problem for him. Communicating with the students and the seniors was themajor problem that he faced being a foreign student. He almost took 6-7 months to overcome this problem. After that, approaching his fellow students was not a problem. The diverse nature of India changed his lifestyle in a way that he was able to adapt.

He got the exposure related to academic and social life in India which he did not get in Saudi. The exposure which he got after coming to India, especially Christ in terms of the curricular and cocurricular activities helped him to overcome his problems. Whatever problem he faced,he overcame it by being optimistic. He considers himself as fluid as water, taking the shape of any vessel it's poured into. He strongly believes that he can adjust anywhere with anybody and still remain happy.

Descriptive phenomenological analysis of the interview

- He chose India because of the ample opportunities and exposure, which he would not have got in Saudi. The learning environment is different in both countries, along with cultural differences. 
- The major problem which he faced in India was the communication problem. He was not able to approach either his friends or his seniors initially during his $12^{\text {th }}$ Class.

- He understood the importance of understanding and accepting the new culture within himself before he joined Christ.

- He accepted the new culture,and the people accepted him because of his optimistic nature. Diverse nature of India has changed his lifestyle.

Results of the Cultural intelligence test

- His cognitive CQ and physical CQ was 3.5 which is more than 3 and less than 4.5 , which indicates that his cultural intelligence is average, i.e. he is able to relate with the culture with fewerdifficulties. He is able to understand the new culture with fewerproblems.

- His Emotional CQ was 3.75, which indicates that he has the confidence to deal with people of a different culture.

- Overall if we take an average of his cognitive, physical and emotional CQ, it comes up to 3.78 , which is an average measurement of the cultural quotient. He is able to work and relate to a new culture with fewerdifficulties.

\section{Case Study 2 (Name- Rattiya Dacanay, Place of Origin- Thailand)}

She is a second-year student currently in Christ (Deemed to be University) pursuing her undergraduate program. She is born and brought up in Thailand. She seemed to be an easy-going person. When we asked her about her decision of choosing India for her higher studies, she talked about the exposure and various opportunities which she would get in India. When we asked about the differences in the learning patterns between Thailand and India, she talked about the usage of more practical knowledge in her home country. More attention is given to the theoretical knowledge in India. She talked about the strict rules and regulations of the college here, especially maintaining the dress code etc. In her home country, there were no rules to follow. The 
learning environment was pretty informalin terms of maintaining dress code etc.

When we asked about the cultural shock which she faced after coming to India, her main problem was communication due to language barriers. Initially, in Christ, students used to make fun of her accent. They used to laugh at her accent. Back in her home town, the only medium of conversation was the Thai language. Here she saw most of the students speaking in Hindi. She was not able to converse with the other students because of the language problem. Initially, she faced a problem, but now, she has overcome it. It affected her academic life at that time, but now she feels fine.

Her second problem was adapting to a new environment. The food culture here is very different from Thailand's. However, now she has also adapted the food culture during the course of her living.

Taking about her social life, she faced problems in making friends initially. However, she realised that people in India are friendly, and they accepted her and did not alienate her. She was very positive about her adaptability in India. It took time to adapt to this country, but now she is doing fine.

Descriptive phenomenological analysis of the interview

Food Culture- Rattaya's main difficulty was in accepting the food culture as it was very different from what she used to eat in Thailand. It took some time for her to adapt herself to relate to the new environment.

Communication Problem- She used to speak only Thai Language when she came to India. She learnt English in Christ. Students used to make fun of her because of her language.

Social Life- Initially, she faced problems in making friends because of her accent. But as she said, people in India are friendly who accepted her and involved her in everything.

Results of the Cultural intelligence test

- Cognitive CQ- Rattaya's Cognitive CQ is 3.25, which is more than 3 , but still needs improvement in this area. She is able to confront with the new environment. 
- Physical CQ- Her Physical CQ is 2.5, which is less than the average, thereby calls for an immediate improvement. It is difficult for her to change her body language to relate to other people from the new culture.

- Emotional CQ- Her Emotional CQ is 5, which indicates a true CQ strength. She has enough confidence in herself if she in case deals with people from a different culture. She is confident that she can deal with the unfamiliar cultural situation.

\section{Case Study - 3 (Student Name - Coreana, Place of Origin - Germany)}

Coreana completed her junior school back in her home town after which she moved to India about six years back. She came to India initially to undertake social service projects. She was in Tamil Nadu for about three years before she got admitted into Christ (Deemed to be University) to pursue her higher studies in Journalism Honours. For the years that she worked in Tamil Nadu with various Non-Governmental Organisations, she got acquainted with the state and the people she was working with. It was easy for her to associate with people because of the mutual cause they were all working for. Her family members are in Germany, and they try meeting up once a year during the Christmas break. Through her studies and projects, she found India a very interesting place, and she thus shifted to India with the idea of completing her projects by being in the place of study. It took her some time to adapt to the language and food of the country and overcome cultural differences between Germany and India.

She is currently in her final year for her undergraduate degree, and she feels that the educational environment is indeed different from that of the world outside. International students have been treated differently because of the narrow mindedness of the people. She interned with The Times of India, and she feels that the working environment is better than the educational environment for international students. She also feels that Indian politics is extremely negative and that very few provisions are made for easy stay for international students. She has come across various people from different cultural backgrounds and is very well versed with 
the culture in India. She feels that certain issues faced by her can be taken over by broader mindsets and acceptance.

Results of the Cultural intelligence test

- Cognitive CQ- Coreana's Cognitive CQ is 4, which is more than 3, which reflects that she is able to work and relate in the new cultural environment. She is able to confront with the new environment.

- Physical CQ- Her Physical CQ is 2.5, which is less than the average, thereby calls for an immediate improvement. It is difficult for her to change her body language to relate to other people from the new culture.

- Emotional CQ- Her Emotional CQ is 3.5, which indicates that she has less confidence to deal with people of a different culture than adapting to the lifestyle of a different culture.

\section{Case Study - 4 (Student Name - Jael, Place of Origin - Congo)}

Jael was born and bought up in Congo, Africa. He completed his High School in Congo and came to India for his higher studies. He is currently studying Bachelors of Business Administration in Finance and International Business from Christ (Deemed to be University). When asked why he chose India for his further studies, he said that it was his father's choice to send him here. His father is in a profession where he is in constant contact with Indians from the different cultural background and is familiar with the Indian culture.

Jael took around more than a year to adjust to the cultural changes. He faced major issues with the language and the food. The only language that he knew was French before he came, and it was extremely difficult for him to adapt to English as the medium of language. Indian food is generally spicier from that of the food in Congo, and for almost a month he couldn't eat that food. He also faced issues with the practice of group-ism among fellow Indian students in the university. People tend to create groups on the basis of their cultural backgrounds and don't want to accept people from outside. However, with time Jael started adapting to the new 
culture and slowly took over the cultural shock. Now he loves spicy food and has a great set of friends.

Results of the Cultural intelligence test

- Cognitive CQ- Jael's Cognitive CQ is 4.25 , which is more than 3 , indicates that he is able to work and relate to a new different environment. He is able to confront in the new environment, but he does not plan how he would be going to relate to people from a different culture before he meets them.

- Physical CQ- His Physical CQ is 4.5, which is more than the average, which indicates that he can easily change the way he acts after encountering new cross-cultural changes.

- Emotional CQ- Her Emotional CQ is 4.5, which indicates a true CQ strength. She has enough confidence in herself if she in case deals with people from a different culture. She is confident that she can deal with the unfamiliar cultural situation.

\section{Case Study - 5 (Student Name - Mayank Agarwal, Place of Origin - Nepal)}

Mayank is born and brought up in Nepal. He completed his schooling in Nepal and came to India for his higher studies. He is currently studying Bachelors of Business Administration from Christ (Deemed to be University). Initially, when he came to India, he was bullied by his fellow mates. He was always called by different names. His fellow mates called him a northeastern person because of his eye.

He did not have any cultural shock, since Nepal is one of the neighbour countries of India. He was well versed withthe diverse culture of India when he came to CHRIST. He did not face any difficulties in terms of confronting the new culture of India.

His social life was not good because of him getting bullied. It resulted in psychological problems, which negatively impactedhis academic life.

After some point time, people accepted him because of his friendly nature. Students recognised him as one of his fellow mates. He did 
not have any problem related to food as the food culture was more or less the same in both countries.

Descriptive phenomenological analysis of the interview -

- He hardly had any cultural shock since the culture of both countries are more or less the same.

- He was mocked for his looks because he looked like a northeastern fellow kid.

- He faced problems in the social as well as academic life.

Results of the Cultural intelligence test: -

- Cognitive CQ- Mayank's Cognitive CQ 4, which is more than average, which indicates that he is able to confront himself in the new environment.

- Physical CQ- His Physical CQ is 4.25, which is again more than the average, thereby does not call for an immediate improvement. It is easy to change his body language to relate to other people from the new culture.

- Emotional CQ- Her Emotional CQ is 4.75, which indicates a true CQ strength. He has enough confidence in himself if he in case deals with people from a different culture. He is confident that he can deal with the unfamiliar cultural situation.

\section{Common Problems faced by International Students}

- Communication/Language Issues- Communication was the most common problem found in all the foreign students which they were able to overcome during the course of time.

- Food Culture- Since each studentis from a different country, they faced issues related to food as most of them did not like Indian food initially. But now, since they have adapted themselves to the new environment, each one of them loves Indian food. 
- Psychological Problem- Student from Africa, Germany, and Thailand faced psychological issues because people did not accept them as individuals.

- Casual racism and discrimination by fellow students.

- Lack of social life and the inability to make new friends.

\section{Techniques used to overcome cultural challenges}

- By being positive and optimistic about the situation and not being weighed down by the current situation or hardship.

- Having a broader mindset and accepting everyone as they are.

- Not fretting and giving yourself enough time to naturally adapt and adjust to the new environment and culture

- Being always willing to interact with more and more people

- Researching about the culture beforehand to not be overwhelmed by the new environment.

- Having a friendly attitude towards peers

\section{Conclusion}

The objective of the study was to assess the role of cultural intelligence in abridging the problems of cross-cultural differences among foreign students in Indian universities. We selected a sample comprising a number of foreign students studying in Indian universities. While many other studies have been carried out on cultural intelligence and foreign students, none of them specifically focus on the Indian context, despite India being such a culturally diverse country. On questioning about the challenges that they faced due to the cultural shock, theiranswers differed from one person to another based on their experiences in the new environment. However, most of them have a great cognitive cultural intelligence, indicating that they are comfortable with adapting to a new culture, while some of them are low on physical cultural intelligence, which indicates the inability to deal with body language while meeting with people from different cultures. Most of them seem to have a strong emotional cultural intelligence. We 
thus conclude that with the reduction in global boundaries, cultural intelligence is one of the abilities required for foreign students to help them interact with people from various cultural backgrounds. Since India is considered as a friendly country, most people do accept international students but not everyone. Just like foreign students take time to adjust, local students also take time to accept them.

We can infer from the analysis of the various case studies that most foreign students coming to India face various challenges, most of which are cultural in nature in terms of having to adjust with different customs, different accepted behaviours,food, language and beliefs. These issues make it difficult for international students to adapt toIndia. Thus, if these international students are more culturally aware and intelligent, they won't face any culture shock and will be able to accustom themselves to this new environment quickly with lesser difficulty.

At the same time, there were many cases where local students were insensitive about their international peers, and these students went through casual racism, discrimination and inability to make friends. A lot of thisbehaviour is induced due to the lack of cultural awareness among local students which make them ignorant and inconsiderate giving international students a hard time. Thus, having local students being more exposed to international cultures and being more culturally aware can enable them to be more accepting of their international peers and ensure no cultural clashes among students from different parts of the world.

Thus we can conclude that it is very evident that the major cause of friction between international and local students is due to ignorance about each other's cultures and customs and having a very narrow view of the world. Therefore, ensuring greater cultural quotient among students can ensure cultural intelligence acts as a mediating factor for international students adaptability in India.

\section{Suggestions}

Since the research helps in establishing that cultural intelligence can help in reducing problems faced by international students in foreign countries the following are suggestions based on the 
research thatcan be implemented by universities and colleges across the world to increase cultural intelligence in their institutions

- Need for the Cross-Cultural training- Cross-Cultural training should be conducted in the colleges or the workplaces for the foreign students as well as for the Indian students. There is a need for this kind of training which will help both the type of students understand each other's culture and accept them. As some of the Indian students are apprehensive in accepting the foreign students, that's why there is a need for this kind of training.

- International students should be considered as an assetEfforts should be made by the host country to accept foreign students as an asset and not a liability.

- Sensitivity training to the local students for accepting international students- This type of training is important for the Indian students, which emphasises on the acceptance of international students. The students should be sensitised towards the international students' culture so that minimal problems are faced by them.

- Establishment of Cultural Intelligence Cell inside the college/workplace- Cultural Intelligence Cell should be established separately inside the college or the workplace where if any problems arise due to the cultural clashes, then it should be solved in this redressal area.

- Being empathetic- Both international and Indian students should be empathetic towards each other in understanding each other's culture.

Limitations of the study

There are several limitations of conducting the study which isas follows

- Limited sample size- The sample size for the study is limited to the number of interviewers. The number of required participants are also limited within the area. 
- Personal bias- Personal bias of the interviewers also arises during the interview. They have their own bias which could affect the way they analyse the responses.

\section{Appendix}

Interview questions-

- Describe the educational learning environment in your country.

- How is it different from the learning environment in our country?

- What are the similarities which you found in both the educational systems?

- Did you face cultural shock? How did you overcome this?

- What are the current problems you are facing in terms of the cross-cultural differences?

- How did people around you make a difference, either good or bad?

- Did you face any problem related to your academic life? 


\section{Survey for measuring Cultural Intelligence (Ang, 2003)}

\section{Diagnosing Your Cultural Intelligence}

These statements reflect different facets of cultural intelligence. For each set, add up your scores and divide by four to produce an average. Our work with large groups of managers shows that for purposes of your own development, it is most useful to think about your three scores in comparison to one another. Generally, an average of less than 3 would indicate an area calling for improvement, while an average of greater than 4.5 reflects a true CQ strength.

Rate the extent to which you agree with each statement, using the scale: 1 = strongly disagree, 2 = disagree, 3 = neutral, 4 = agree, 5 = strongly agree .

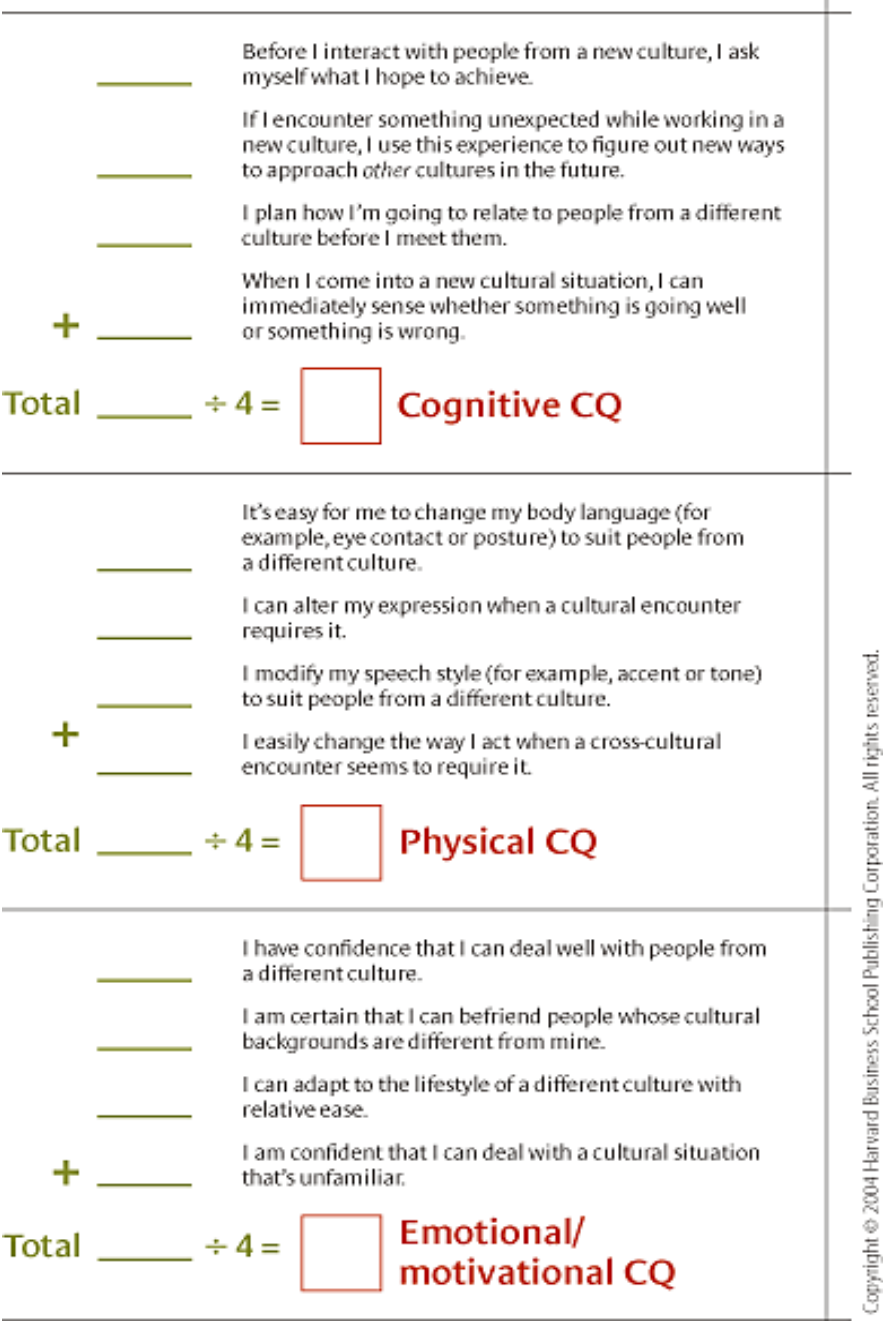




\section{References}

Biggest Diversity Issues in The Workplace. (2019). Retrieved from https:// www.thiswayglobal.com/diversity/top-diversity-issues-inthe-workplace/

Akinkugbe, M. O. (2013). The impacts of studying in a different cultural environment.

Ang, P. C. (2003). Cultural Intelligence - Individual Interactions Across Cultures. Stanford, California: Stanford Business Books.

Arthur. (2004). Counseling international students: Clients from around the world.

Boonchum, P. (2009). A Study of Self-Identity Changes and Correlation of Influential Factors of Thai Students Studying English.

Bradley, S. L. (2002). Relation between general self-efficacy, assertiveness, spirituality, and acculturative stress among.

Campbell, N. (2011). Promoting Intercultural Contact on Campus: A Project to Connect and Engage International and Host Students.

Chase, S. G. (2011). Internationalisation of higher education: integrating international students into Canadian academic environment.

Deardorff, D. K. (2006). Identification and assessment of intercultural competence as a student outcome of internationalization. Journal of studies in international education, 10(3), 241-266.

Evan, D., \& Wooda, H. Y. (2015). Short-term cross-cultural study tours: impact on cultural intelligence. The International Journal of Human Resource Management, 558-570.

Faruk, S. \&Ahina, S. G. (2014). Cultural intelligence (CQ) in action: The effects of personality and international assignment on the development of CQ. International Journal of Intercultural Relations, 152163.

Fischer, R. (2011). Cross-cultural training effects on cultural essentialism beliefs. International Journal of Intercultural Relations, 767-775.

Gazzoli, G. (2013). International Students'Acculturation and Adaptation: The case of an indigenous group studying in Switzerland.

Glazer, C. T. (2017). Cross-Cultural Competence and Cultural Intelligence in the Workplace. SpringerBriefs .

Guzel, H. (2016). Demographic factors inrelation to accularitation and Acculturative stress: A compasrison of domestic and international students. The United States.

Hartini, H. (2017). The effects of cultural intelligence on international students.Malaysia: International Journal of Business, Economics and Law, 12(2).

Higgins, I. A. (2005). Global Leadership success through emotional and cultural intelligence. 
Inkpen, S. A. (2008). Cultural Intelligence and Offshore Outsourcing Success: A Framework of Firm-Level Intercultural Capability.

Eisenberg, J., Lee, H. J., Brück, F., Brenner, B., Claes, M. T., Mironski, J., \& Bell, R. (2013). Can business schools make students culturally competent? Effects of cross-cultural management courses on cultural intelligence. Academy of Management Learning \& Education, 12(4), 603-621.

Jian Wang, D. G. (2002). Cross-Cultural Communication: Implications for Effective Information Services In Academic Libraries. Johns Hopkins University Press.

Lipson, C. (2008). Succeeding as an International Student in the United States and Canada.

Livermore. (2008). The cultural intelligence difference: master the one skill you can't do without in today's global economy.AMACOM, 14-16.

Wajid, M. (2017, November 29). Problems Faced by International Student. Retrieved from https://cchowler.com/2697/editorial/problemsfaced-by-international-students/

Chao, M. M., \&Takeuchi, R. (2016). Enhancing cultural intelligence: The roles of implicit culture beliefs and adjustment. Personnel Psychology, 1-36.

Mendenhall, J. S. (1990). Cross-Cultural Training Effectiveness: A Review and a Theoretical Framework for Future Research.

Miriam Erez, A. L. (2013). Going Global:Developing Management Students' Cultural Intelligence and Global Identity in Culturally Diverse Virtual Teams. Academy of Management Learning $\mathcal{E}$ Education,10(3), 330-355.

Nishii, L. H. (2013). The Benefits of Climate for Inclusion for GenderDiverse Groups.

Peterson, P. C. (2017, November 30). The Elusive Cultural Chameleon: Cultural Intelligence as a New Approach to Intercultural Training for the Global Manager. Retrieved from journals.aom.org: https://doi.org/10.5465/amle.2004.12436826

Prashant K. Nanda, A. R. (2018, August 17). More Indians going abroad for studies, but foreign students aren't coming in. Retrieved from https:// www.livemint.com/Education/qVtlWO1E9D923fiDD2o69I/ More-Indians-going-abroad-for-studies-but-foreign-students.html

Qing $\mathrm{Gu}, \mathrm{M}$. S. (2009). Learning and growing in a 'foreign' context: intercultural experiences of international students.

Rebecca, J., \& Reichard, S. A. (2015). Engagement in cultural trigger events in the development of cultural Competence. Academy of Management Learning E Education, 14(4), 461-481.

Ryan, J. (2011). Teaching and learning for international students: Towards a transcultural approach. 
Serjanaj, A. (2016). Sociology by Teachers, Senior Students and Professional Master Students for Teaching. European Journal of Multidisciplinary Studies.

Sümer, S. (2009). International students' psychological and sociocultural adaptation in the united states.

Tay, C. K. (2007). Cultural Intelligence:Its measurement and effects on cultural judgment and decision making,cultural adaptation, and task performance. Management and Organization Review, 335-371.

Thomson, G. (2006). Cultural stress among students at an Australian University. Australia.

Toledano, A. P. (2017). Global team members' performance and the roles of cross-cultural training, cultural intelligence, and contact intensity: the case of global teams in IT offshoring sector. The International Journal of Human Resource Management, 1-27.

Walton, C. A. (2012). Homesickness and Adjustment in University Students.

Wang, K. T. (2015). Cultural intelligence trajectories in new international students: Implications for the development of cross-cultural competence. International Perspective in Psychology: Research. 